\title{
Deguelin inhibits proliferation and migration of human pancreatic cancer cells in vitro targeting hedgehog pathway
}

\author{
WEN ZHENG, SHILIU LU, HAOLEI CAI, MUXING KANG, WENJIE QIN, CHAO LI and YULIAN WU
}

Department of Surgery, The Second Affiliated Hospital of Zhejiang University, Hangzhou, Zhejiang 310009, P.R. China

Received December 19, 2014; Accepted February 11, 2016

DOI: $10.3892 / 01.2016 .4928$

\begin{abstract}
Pancreatic cancer (PC) is a highly lethal malignancy with few effective therapies. Deguelin, a natural compound of the flavonoid family of products, has been reported to have an inhibitory effect on various cancers. In the present study, we investigated whether deguelin had antitumor efficacy in PC. Deguelin treatment was observed to inhibit growth and induce apoptosis in two PC cell lines (Bxpc-3 and Panc-1). In addition, it inhibited migration and invasion in these two cell lines. The activation of the hedgehog ( $\mathrm{Hh})$ signaling pathway, as well as matrix metalloproteinases (MMP)-2 and MMP-9, was suppressed by deguelin. These results suggest that deguelin may be a potential chemotherapeutic agent for PC, possibly through the suppression of the Hh signaling pathway.
\end{abstract}

\section{Introduction}

Pancreatic cancer (PC) is one of the most aggressive malignancies, and is ranked as the fourth leading cause of cancer-related mortality in developed countries $(1,2)$. More than $85 \%$ of patients have already suffered local infiltration or distant metastasis at the time of initial diagnosis due to the extremely poor early diagnosis rate and highly aggressive behavior of PC (3). The overall 5-year survival rate is less than 5\%. Thus, novel effective therapeutic methods or agents for preventing and controlling this disease are urgently required.

Deguelin is a natural compound of the flavonoid family of products isolated from several plant species, including Derris trifoliata Lour and Mundulea sericea (Leguminosae) (4). Several studies have already demonstrated its excellent potential as an anticarcinogenic and antiproliferative agent against various malignant tumors including gastric, lung and breast carcinoma, by targeting apoptosis, cell cycle arrest

Correspondence to: Professor Yulian Wu, Department of Surgery, The Second Affiliated Hospital of Zhejiang University, 88 Jiefang Road, Hangzhou, Zhejiang 310009, P.R. China

E-mail:wuyulian@medmail.com.cn

Abbreviations: PC, pancreatic cancer; Hh, hedgehog

Key words: pancreatic cancer, deguelin, hedgehog signaling pathway and anti-angiogenesis (5-7). Deguelin also exhibits effects of anti-metastasis $(7,8)$. It inhibits cancers through a number of pathways, including the PI3K-Akt, HIF-1-VEGF, IKK-I $\kappa \mathrm{B} \alpha-\mathrm{NF}-\kappa \mathrm{B}$, EMT and AMPK-mTOR-survivin pathways (4-7). However, there are few studies on deguelin regulating the hedgehog $(\mathrm{Hh})$ signaling pathway, an essential pathway in tumor growth and metastasis. In addition, the correlation between deguelin and PC has rarely been researched to date.

The Hh signaling pathway transmits information to embryonic cells required for proper development. Mammals have three Hh homologs: Desert (Dhh), Indian (Ihh) and Sonic (Shh), all of which have distinct as well as overlapping roles (9-11). The general organization of the Hh pathway consists of a series of repressive interactions. In the absence of $\mathrm{Hh}$ proteins (off-state) as the Hh receptors, Patched 1 (PTCH1), a 12-transmembrane protein, suppresses the otherwise constitutively active signaling receptor Smoothened (12-18). In the off-state, Suppressor of fused (SUFU) suppresses Hh signaling by regulating the localization of the Gli transcription factors $(19,20)$. Glil is an effective activator of protein kinase A and itself. Therefore, Gli1 localization within the nucleus is a biomarker of $\mathrm{Hh}$ activity (21). Matrix metalloproteinases (MMPs), a family of zinc-dependent endopeptidases, play significant roles in tumor tissue remodeling, and are associated with a number of physiological or pathological processes. MMP-2 and MMP-9 are considered to be particularly significant in metastasis $(22,23)$. It is well known that the activation of $\mathrm{Hh}$ has been implicated in the development of cancers in various sites, including prostatic, gastric, esophageal and ovarian organs (24-27).

In the present study, we further explored the effects of deguelin as a chemotherapeutic agent against human PC cells, and investigated its mechanism.

\section{Materials and methods}

Cell culture and reagents. Human PC cell lines Panc-1 and Bxpc-3 were purchased from American Type Culture Collection (ATCC; Rockville, MD, USA). The Panc-1 cells were cultured in Dulbecco's modified Eagle's medium (Gibco, Rockville, MD, USA) supplemented with $10 \%$ fetal bovine serum (FBS), $100 \mathrm{U} / \mathrm{ml}$ penicillin $\mathrm{G}$ and $100 \mathrm{U} / \mathrm{ml}$ streptomycin in a humidified incubator containing $5 \% \mathrm{CO}_{2}$ in air at $37^{\circ} \mathrm{C}$. The Bxpc-3 cells were cultured in RPMI-1640 medium (Gibco) containing supplements as above. Deguelin was purchased from Sigma-Aldrich (St. Louis, MO, USA) and dissolved in dimethyl 
sulfoxide (DMSO) to make $0.1 \mathrm{mmol} / \mathrm{l}$ stock solution and stored at $-20^{\circ} \mathrm{C}$. The final concentration of DMSO was $<0.1 \%$.

Cell growth inhibition assay. Cell growth-inhibitory curves of 7 days were observed by Cell Counting Kit-8 (CCK-8; Mai Bio, Ltd. Shanghai, China) assay. Briefly, cells were plated at a density of $2 \times 10^{3}$ cells/well in 96 -well microtiter plates. Following treatment, $20 \mu \mathrm{l}$ CCK- 8 solution was added to each well and further incubated for 1-3 $\mathrm{h}$. Then absorbance was measured with an absorbance reader (Bio-Tek ELx800, Winooski, VT, USA) at a wavelength of $450 \mathrm{~nm}$.

Flow cytometric assessment of apoptosis. The Annexin V-FITC apoptosis detection kit (Nanjing KeyGen Biotech Co., Ltd., Nanjing, China) was used for flow cytometric analysis of apoptosis. Cells were treated with deguelin for $48 \mathrm{~h}$ on a six-well plate, then $5 \times 10^{5}$ cells were harvested and washed twice with phosphate-buffered saline, then resuspended in $500 \mu \mathrm{l}$ binding buffer. Annexin V-FITC (5 $\mu$ l) and propidium iodide were added to each sample and incubated for $15 \mathrm{~min}$ in the dark. The stained cells were analyzed directly by flow cytometry using the CellQuest program (Becton Dickinson, San Jose, CA, USA).

Wound-healing assay. Cell migration in vitro was assessed by wound healing assay. The culture insert (Ibidi, Martinsried, Germany) was placed in a clean and dry six-well plate in advance. Suspended cells (70 $\mu \mathrm{l})$ were loaded at a density of $6 \times 10^{5} / \mathrm{ml}$. When a confluent layer was formed, medium with $0.5 \%$ FBS was added the well after the culture insert was removed. Acquired images at 0,12 and $24 \mathrm{~h}$ of follow-up incubation were analyzed online at wimasis.com.

Transwell migration assay. Transwell migration assays were performed using polycarbonate membrane Transwell inserts (Corning Incorporated, Corning, NY, USA) with an 8.0- $\mu \mathrm{m}$ pore size and $6.5-\mathrm{mm}$ membrane diameter on 24 -well plates. The lower chambers were filled with $600 \mu \mathrm{l}$ medium $(10 \%$ FBS), and the upper chambers were loaded with cells at a density of $1 \times 10^{5}$ cells/well) in $200 \mu 1$ medium (2\% FBS). Following incubation for $24 \mathrm{~h}$, the membranes were fixed in $4 \%$ paraformaldehyde for $20 \mathrm{~min}$ and stained with hematoxylin and eosin for $10 \mathrm{~min}$, respectively. Cells on the upper surface of the membranes were removed with cotton swabs. Cells adhered to the lower surface were observed under the microscope.

Western blot analysis. Cells were lysed with RIPA buffer (Sigma-Aldrich) supplemented with a complete protease inhibitor cocktail (Roche, Basel, Switzerland). Following centrifugation at $13,000 \mathrm{x}$ g for $30 \mathrm{~min}$, the supernatant was collected and protein concentration was determined using a bicinchoninic acid protein assay kit (Pierce Biotechnology, Rockford, IL, USA). Protein (40 $\mu \mathrm{g})$ was separated in $8-10 \%$ sodium dodecyl sulphate-polyacrylamide gel and transferred to polyvinylidene difluoride membranes (Bio-Rad, Hercules, CA, USA). The transblotted membranes were blocked in Tris-buffered saline with Tween-20 (10 mM Tris-HCL pH 7.4, $150 \mathrm{mM} \mathrm{NaCl}$ and $0.1 \%$ Tween-20) with $5 \%$ skimmed milk for $1.5 \mathrm{~h}$ at room temperature, then incubated with primary antibodies overnight at $4^{\circ} \mathrm{C}$, followed by horseradish peroxidase-conjugated secondary antibodies. The immunoreactive bands were visualized using enhanced chemiluminescence (Biological Industries, Beit Haemek, Israel) and exposed to X-ray films. All the antibodies were procured from Cell Signaling Technology, Inc. (Danvers, MA, USA).

Statistical analysis. The results were expressed as the means \pm standard error. All experiments were performed in triplicate. The one-way ANOVA or two-tailed Student's t-test were used to determine the statistical significance between two unpaired groups. $\mathrm{P}<0.05$ was considered to indicate a statistically significant difference. Analyses were performed using SPSS 13.0 statistical software package (SPSS Inc., Chicago, IL, USA).

\section{Results}

Deguelin inhibits the growth of PC cells. To assess the effects of deguelin on PC cell growth, Bxpc-3 and Panc-1 cells were treated with deguelin at increasing concentrations $(0-20 \mu \mathrm{M})$ for a week. Deguelin inhibited the growth of the two cell lines in a dose- and time-dependent manner under no interference of the solvent (DMSO; Fig. 1A and B). These results indicate that deguelin was an effective inhibitor of PC cell proliferation, and Bxpc-3 cells were more sensitive to deguelin compared with Panc-1 cells.

Deguelin induces apoptosis of PC cells. We subsequently investigated whether deguelin induced apoptosis in PC cells. Flow cytometry revealed that treatment with deguelin for $48 \mathrm{~h}$ induced apoptosis in the two cell lines. Exposure to deguelin $(5 \mu \mathrm{M})$ induced apoptosis by up to $18.1 \%$ in Bxpc-3 and $15.1 \%$ in Panc-1 cells. The higher concentration $(10 \mu \mathrm{M})$ induced more apoptosis (36.1\% in Bxpc-3, 23.1\% in Panc-1 cells) (Fig. 2A). Western blot analysis demonstrated that the expression of two apoptosis-related proteins, cleaved caspase- 3 and PARP, significantly increased with the concentration of deguelin (Fig. 2B). These data suggested that deguelin induces apoptosis through the activation of caspase- 3 and the cleavage of PARP.

Deguelin inhibits migration and invasion of PC cells. To verify whether deguelin inhibits the migration and invasion ability of PC cells, wound healing assay and Transwell cell invasion assay were performed. The data from wimasis.com demonstrated that the cell-covered area of deguelin-treated cells was smaller than that of untreated cells after 12 and $24 \mathrm{~h}$ (Fig. 3A and B).

The results of the Transwell assay revealed that cell invasion in the deguelin-treated group was notably decreased compared with that in the control group (Fig. 3C and D). The results suggested that deguelin inhibited the invasion and migration capability of the two PC cell lines.

Deguelin downregulates MMP-2 and MMP-9 in Bxpc-3 and Panc-1 cells. In order to verify our theory on the mechanism of deguelin influencing PC, the expression levels of MMP-2 and MMP-9 were measured. Bxpc-3 and Panc-1 cells were treated with various concentrations of deguelin for $48 \mathrm{~h}$, and then total protein was extracted for western blot analysis. We noted that the levels of MMP-2 and MMP-9 protein were gradually decreased with the increase in drug concentration (Fig. 4A). 

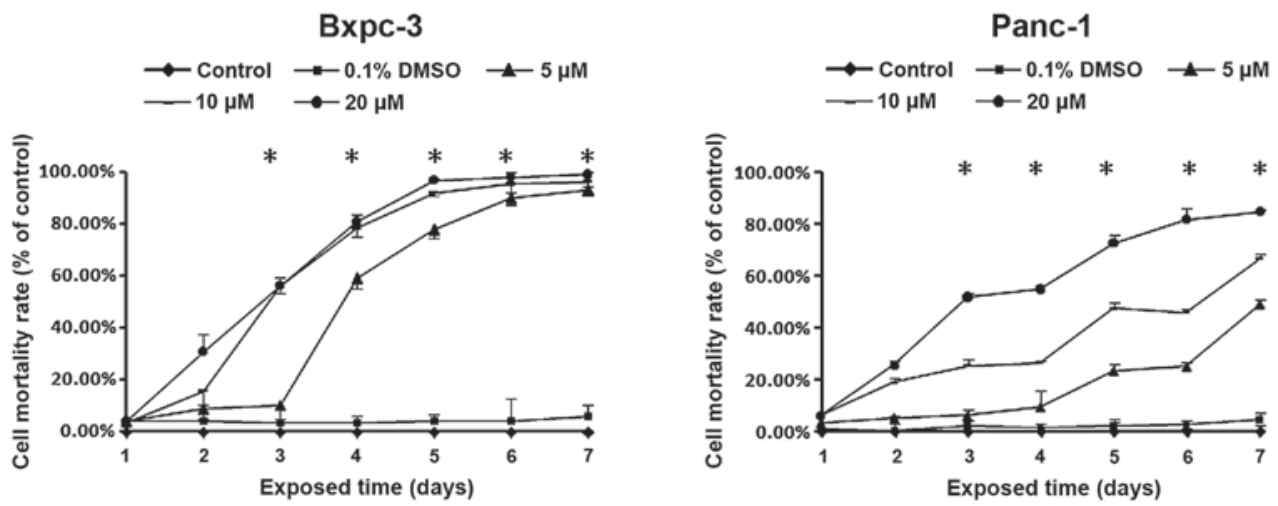

Figure 1. Deguelin inhibits the proliferation of two pancreatic cancer cell lines. Bxpc-3 and Panc-1 cells were treated with various concentrations of deguelin or solvent ( $0.1 \%$ dimethyl sulfoxide) for seven days. The viability was assessed by Cell Counting Kit- 8 . Deguelin was shown to induce a dose- and time-dependent increase in the cell mortality rate in the two cell lines ("P<0.04, compared with control groups). DMSO, dimethyl sulfoxide.
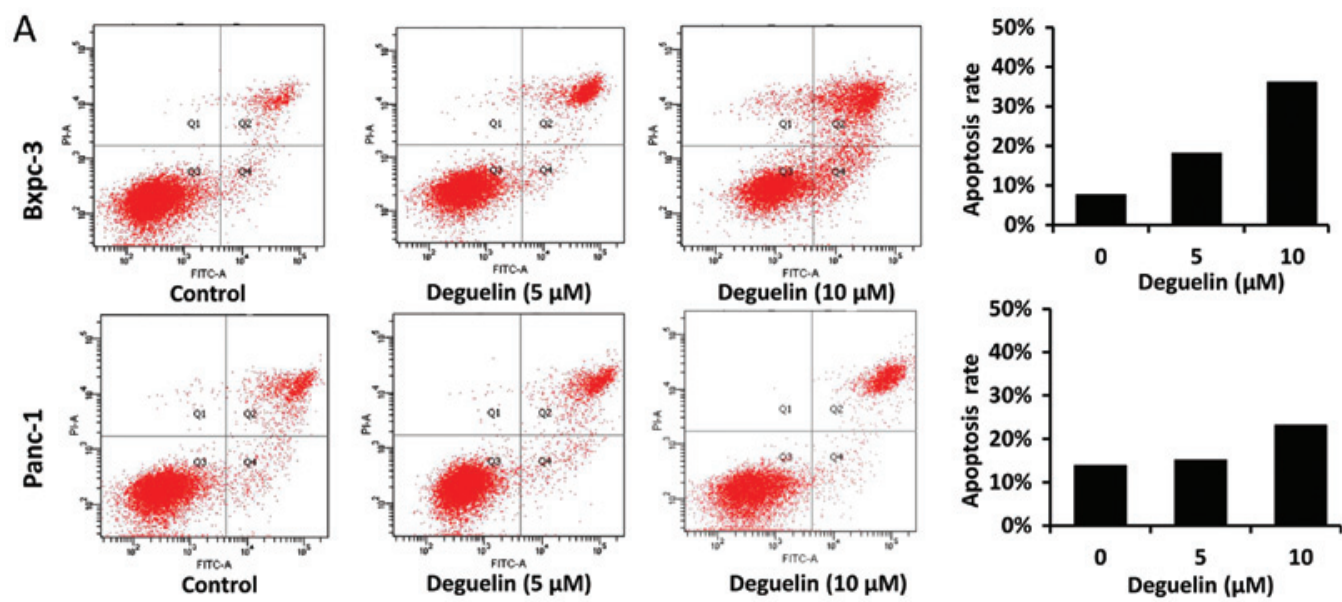

B
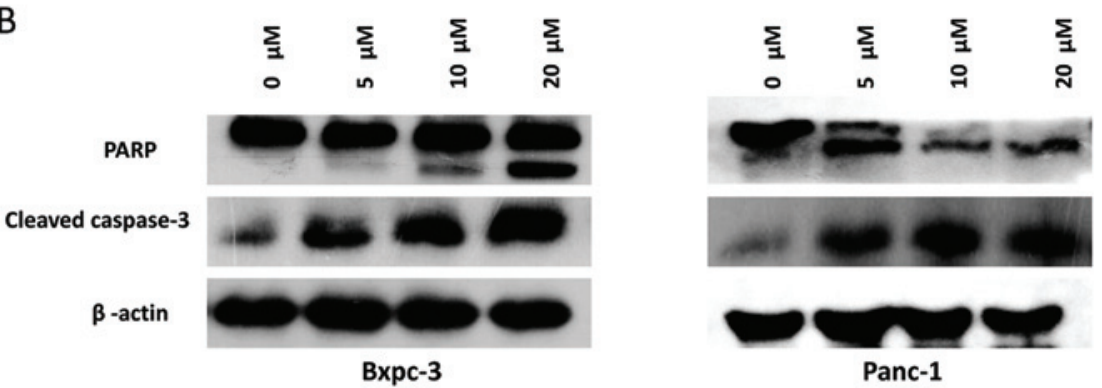

Figure 2. Deguelin induces apoptosis in two pancreatic cancer cell lines. (A) Flow cytometry revealed that the apoptosis rate of pancreatic cancer cells increased when treated with deguelin. (B) The expression of PARP and cleaved caspase-3 was upregulated by deguelin. $\beta$-actin served as the internal control.

The results revealed that deguelin inhibits metastasis in PC by suppressing the activation of MMP-2 and MMP-9.

Deguelin inhibits Hh signaling pathway in Bxpc-3 and Panc-1 cells. To further investigate whether deguelin regulates PC through Hh signaling, we sought to examine the protein expression levels of several key members of this pathway. The expression of Gli1 was downregulated by the treatment of deguelin in Bxpc-3 and Panc-1 cells. Conversely, the expression of SUFU was upregulated. PTCH1 and PTCH2 were able to suppress Hh earlier than SUFU, and their levels were increased in line with our expectations. Furthermore, as the ligand located at the starting point of the Hh signaling pathway,
Shh is important for the regulation of Hh. The spliceosome of Shh was increased following treatment with deguelin (Fig. 4B). In sumary, the results regarding the change of ligands in $\mathrm{Hh}$ indicated that deguelin inhibited the Hh signaling pathway.

\section{Discussion}

PC patients are noted to have a rather poor survival rate due to the high aggressiveness and early metastasis of the disease. In recent years, various methods have been used to restrain PC or increase the possibility of surgery. In our study, deguelin demonstrated the potential to inhibit proliferation, induce apoptosis and suppress migration in PC cells. 

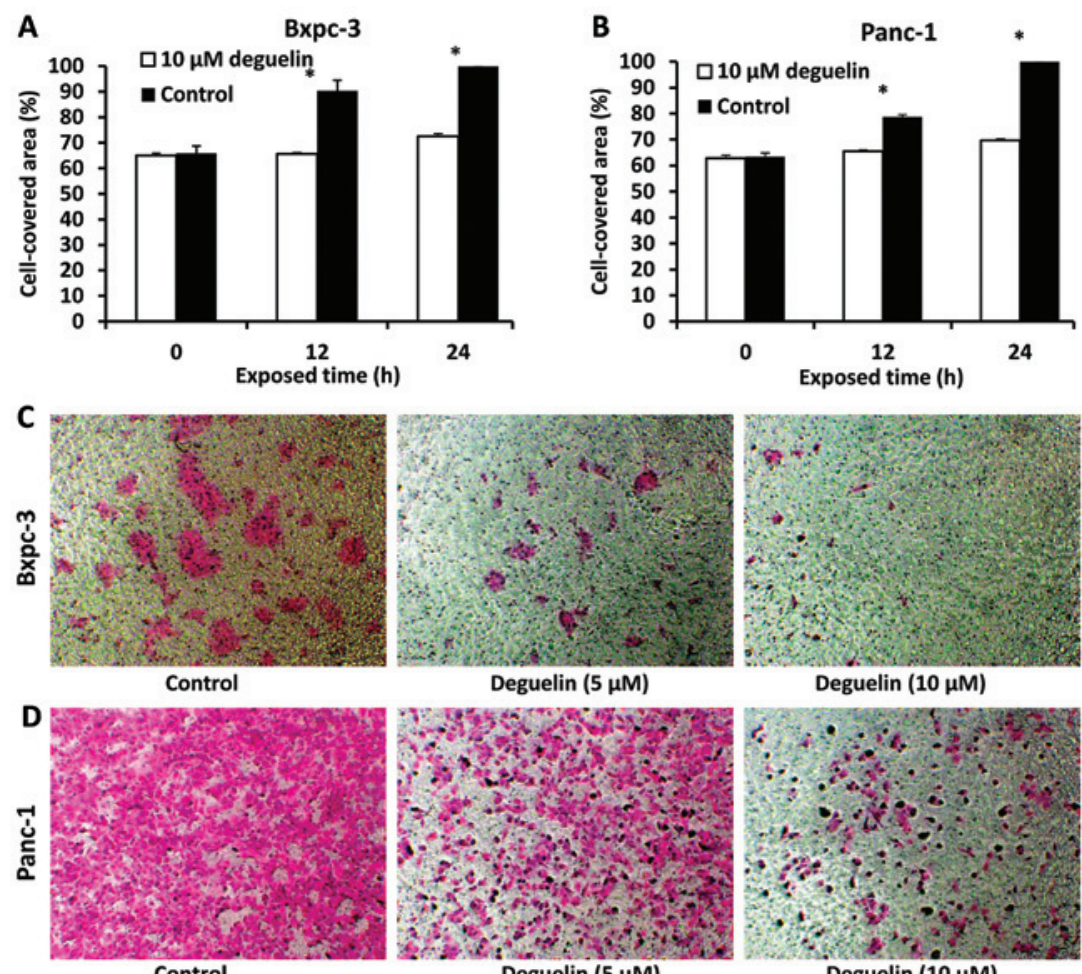

Deguelin $(10 \mu \mathrm{M})$

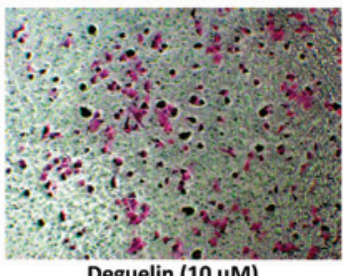

Figure 3. Deguelin suppresses migration and invasion of pancreatic cancer cells. Compared with the control, deguelin (10 $\mu \mathrm{M})$-treated (A) BXPC-3 and (B) Panc-1 cells exhibited extremely slow wound healing at 12 and $24 \mathrm{~h}$. A smaller cell-covered area was present in deguelin-treated cells compared with untreated cells ("P<0.05). Fewer (C) BXPC-3 or (D) Panc-1 cells migrated to the lower surface of the Transwell when treated with various concentrations of deguelin for $48 \mathrm{~h}$ compared with untreated cells. Images were acquired from an optical microscope (stain, hematoxylin and eosin; magnification, x10).

A

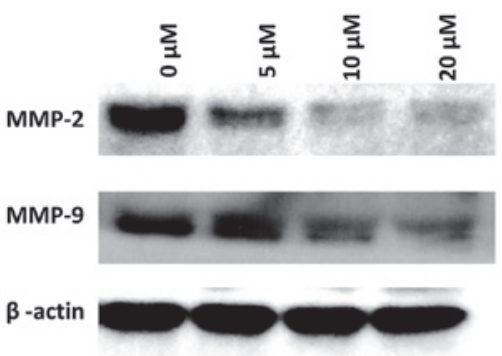

Bxpc-3

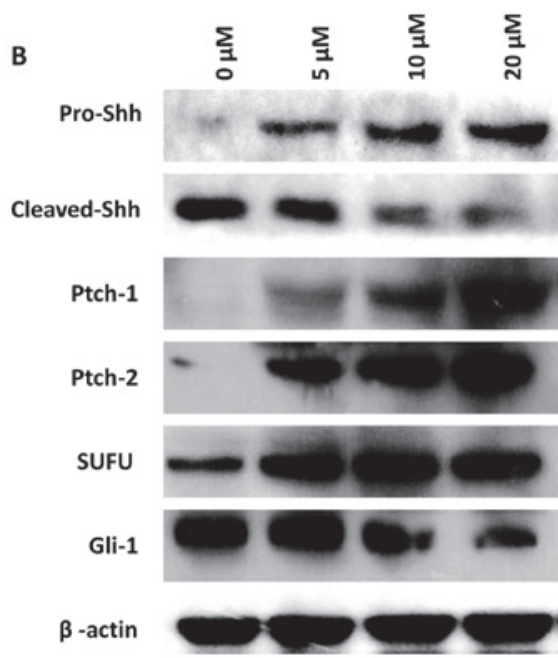

Bxpc-3
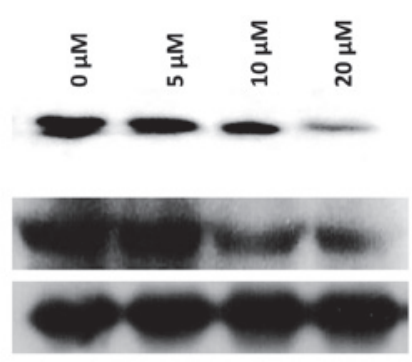

Panc-1

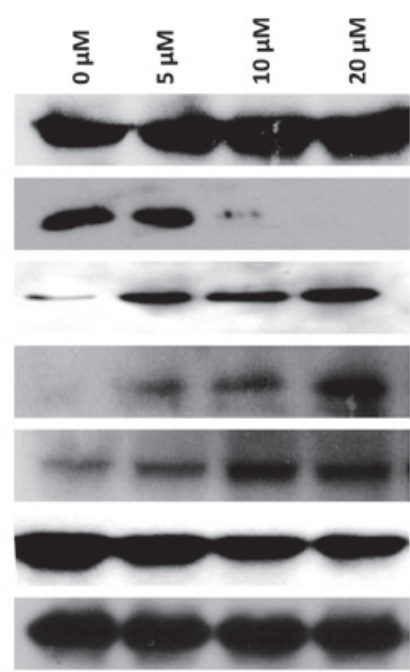

Panc-1

Figure 4. (A) Deguelin inhibits the expression of matrix metalloproteinase (MMP)-2 and MMP-9 and the hedgehog signaling pathway in pancreatic cancer (PC) cells. PC cells were treated with various concentrations of deguelin for $48 \mathrm{~h}$. (B) The expression of MMP-2 and MMP-9 was assessed. The expression of the hedgehog signaling pathway was determined following treatment with deguelin for $48 \mathrm{~h}$. $\beta$-actin served as the internal control. 
Deguelin is known to exhibit significant antitumor properties in various types of cancer. However, its mechanisms have not been fully elucidated.

The components of the Shh pathway are highly expressed in PC cell lines $(28,29)$. Our results revealed that deguelin inhibits PC cells proliferation by suppressing the Hh pathway.

MMPs, in particular MMP-2 and MMP-9, play a crucial role in tumor metastasis and invasion $(23,30,31)$. The expression of MMP-2 and MMP-9 may be regulated by Hh pathways (32-34). Our results demonstrated that deguelin was capable of modulating migration and invasion in PC cells by regulating the expression of MMP-2 and MMP-9. The interference of the Hh pathway may induce the changes in MMP-2 and MMP-9.

In conclusion, the results from the present study confirm that deguelin has the potential to inhibit the growth, migration and invasion in $\mathrm{PC}$ by suppressing the Hh signaling pathway. However, further research is necessary in order to obtain further information before these results may be used in the clinic.

\section{Acknowledgements}

This study was supported by the National Natural Science Foundation of China (no. 81301889).

\section{References}

1. Maitra A and Hruban RH: Pancreatic cancer. Annu Rev Pathol 3 157-188, 2008

2. Pekala KR, Ma X, Kropp PA, Petersen CP, Hudgens CW, Chung $\mathrm{CH}$, Shi C, Merchant NB, Maitra A, Means AL and Gannon MA: Loss of HNF6 expression correlates with human pancreatic cancer progression. Lab Invest 94: 517-527, 2014.

3. Jemal A, Murray T, Samuels A, Ghafoor A, Ward E and Thun MJ: Cancer statistics, 2003. CA Cancer J Clin 53: 5-26, 2003.

4. Wang Y, Ma W and Zheng W: Deguelin, a novel anti-tumorigenic agent targeting apoptosis, cell cycle arrest and anti-angiogenesis for cancer chemoprevention. Mol Clin Oncol 1: 215-219, 2013.

5. Mehta R, Katta H, Alimirah F, Patel R, Murillo G, Peng X, Muzzio M and Mehta RG: Deguelin action involves c-Met and EGFR signaling pathways in triple negative breast cancer cells. PLoS One 8: e65113, 2013.

6. Lee H, Lee JH, Jung KH and Hong SS: Deguelin promotes apoptosis and inhibits angiogenesis of gastric cancer. Oncol Rep 24: 957-963, 2010.

7. Hu J, Ye H, Fu A, Chen X, Wang Y, Chen X, Ye X, Xiao W, Duan X, Wei Y and Chen L: Deguelin - an inhibitor to tumor lymphangiogenesis and lymphatic metastasis by downregulation of vascular endothelial cell growth factor-D in lung tumor model. Int J Cancer 127: 2455-2466, 2010.

8. Mehta RR, Katta H, Kalra A, Patel R, Gupta A, Alimirah F, Murillo G, Peng X, Unni A, Muzzio M and Mehta RG: Efficacy and mechanism of action of Deguelin in suppressing metastasis of 4T1 cells. Clin Exp Metastasis 30: 855-866, 2013.

9. Adolphe C, Narang M, Ellis T, Wicking C, Kaur P and Wainwright B: An in vivo comparative study of sonic, desert and Indian hedgehog reveals that hedgehog pathway activity regulates epidermal stem cell homeostasis. Development 131: 5009-5019, 2004.

10. Pathi S, Pagan-Westphal S, Baker DP, Garber EA, Rayhorn P, Bumcrot D, Tabin CJ, Blake Pepinsky R and Williams KP: Comparative biological responses to human Sonic, Indian and Desert hedgehog. Mech Dev 106: 107-117, 2001.

11. Zhang XM, Ramalho-Santos M and McMahon AP: Smoothened mutants reveal redundant roles for Shh and Ihh signaling including regulation of $L / R$ asymmetry by the mouse node. Cell 105: 781-792, 2001.

12. Chen Y and Struhl G: Dual roles for patched in sequestering and transducing Hedgehog. Cell 87: 553-563, 1996.

13. Ingham PW and McMahon AP: Hedgehog signaling in animal development: paradigms and principles. Genes Dev 15: 3059-3087, 2001.
14. McMahon AP, Ingham PW and Tabin CJ: Developmental roles and clinical significance of hedgehog signaling. Curr Top Dev Biol 53: 1-114, 2003

15. Motoyama J, Liu J, Mo R, Ding Q, Post M and Hui CC: Essential function of Gli2 and Gli3 in the formation of lung, trachea and oesophagus. Nat Genet 20: 54-57, 1998.

16. Motoyama J, Takabatake T, Takeshima K and Hui C: Ptch2, a second mouse Patched gene is co-expressed with Sonic hedgehog. Nat Genet 18: 104-106, 1998.

17. Smyth I, Narang MA, Evans T, Heimann C, Nakamura Y, Chenevix-Trench G, Pietsch T, Wicking $\mathrm{C}$ and Wainwright BJ: Isolation and characterization of human patched 2 (PTCH2), a putative tumour suppressor gene in basal cell carcinoma and medulloblastoma on chromosome 1p32. Hum Mol Genet 8: 291-297, 1999.

18. Stone DM, Hynes M, Armanini M, Swanson TA, Gu Q, Johnson RL, Scott MP, Pennica D, Goddard A, Phillips H, et al: The tumour-suppressor gene patched encodes a candidate receptor for Sonic hedgehog. Nature 384: 129-134, 1996.

19. Barnfield PC, Zhang X, Thanabalasingham V, Yoshida M and Hui CC: Negative regulation of Gli1 and Gli2 activator function by Suppressor of fused through multiple mechanisms. Differentiation 73: 397-405, 2005.

20. Méthot N and Basler K: Suppressor of fused opposes hedgehog signal transduction by impeding nuclear accumulation of the activator form of Cubitus interruptus. Development 127: 4001-4010, 2000.

21. Matsushita S, Onishi H, Nakano K, Nagamatsu I, Imaizumi A, Hattori M, Oda Y, Tanaka M and Katano M: Hedgehog signaling pathway is a potential therapeutic target for gallbladder cancer. Cancer Sci 105: 272-280, 2014.

22. Freije JM, Balbin M, Pendás AM, Sánchez LM, Puente XS and López-Otín C: Matrix metalloproteinases and tumor progression. Adv Exp Med Biol 532: 91-107, 2003.

23. Vihinen P, Ala-Aho R and Kähäri VM: Matrix metalloproteinases as therapeutic targets in cancer. Curr Cancer Drug Targets 5: 203-220, 2005.

24. Karhadkar SS, Bova GS, Abdallah N, Dhara S, Gardner D, Maitra A, Isaacs JT, Berman DM and Beachy PA: Hedgehog signalling in prostate regeneration, neoplasia and metastasis. Nature 431: 707-712, 2004

25. Liao X, Siu MK, Au CW, Wong ES, Chan HY, Ip PP, Ngan HY and Cheung AN: Aberrant activation of hedgehog signaling pathway in ovarian cancers: effect on prognosis, cell invasion and differentiation. Carcinogenesis 30: 131-140, 2009.

26. Mori Y, Okumura T, Tsunoda S, Sakai Y and Shimada Y: Gli-1 expression is associated with lymph node metastasis and tumor progression in esophageal squamous cell carcinoma. Oncology 70: 378-389, 2006.

27. Yoo YA, Kang MH, Kim JS and Oh SC: Sonic hedgehog signaling promotes motility and invasiveness of gastric cancer cells through TGF-beta-mediated activation of the ALK5-Smad 3 pathway. Carcinogenesis 29: 480-490, 2008.

28. Li SH, Fu J, Watkins DN, Srivastava RK and Shankar S: Sulforaphane regulates self-renewal of pancreatic cancer stem cells through the modulation of Sonic hedgehog-GLI pathway. Mol Cell Biochem 373: 217-227, 2013.

29. Rodova M, Fu J, Watkins DN, Srivastava RK and Shankar S: Sonic hedgehog signaling inhibition provides opportunities for targeted therapy by sulforaphane in regulating pancreatic cancer stem cell self-renewal. PLoS One 7: e46083, 2012.

30. Hadler-Olsen E, Winberg JO and Uhlin-Hansen L: Matrix metalloproteinases in cancer: their value as diagnostic and prognostic markers and therapeutic targets. Tumour Biol 34: 2041-2051, 2013.

31. Stetler-Stevenson WG: Type IV collagenases in tumor invasion and metastasis. Cancer Metastasis Rev 9: 289-303, 1990.

32. Chen JS, Li HS, Huang JQ, Zhang LJ, Chen XL, Wang Q, Lei J, Feng JT, Liu Q and Huang XH: Down-regulation of Gli-1 inhibits hepatocellular carcinoma cell migration and invasion. Mol Cell Biochem 393: 283-291, 2014

33. Chen M, Qian Y, Dai J and Chu R: The sonic hedgehog signaling pathway induces myopic development by activating matrix metalloproteinase (MMP)-2 in Guinea pigs. PLoS One 9: e96952, 2014.

34. Fan HX, Wang S, Zhao H, Liu N, Chen D, Sun M and Zheng JH: Sonic hedgehog signaling may promote invasion and metastasis of oral squamous cell carcinoma by activating MMP-9 and E-cadherin expression. Med Oncol 31: 41, 2014. 